\title{
Analysis of Problems and Strategies of Physical Education in Colleges and Universities
}

\author{
Xiaoning Wang, Qinghua Shan \\ Shandong Agricultural University, Tai'an Shandong, 271000, China
}

Keywords: Physical education in colleges, Universities student initiative, Teaching quality

\begin{abstract}
With the continuous deepening of the reform of college physical education, extracurricular physical exercise status and role has been recognized and valued, it is no longer the extension and supplement of college physical education, but has its unique form and function of education, which complements each other, shares the task of health education. It is an important part of physical education and health in colleges and universities. Extracurricular physical exercise is the key to realizing the health education of the university and even the lifelong physical education. It is also one of the most important ways to achieve the goal of physical education in colleges and universities. Therefore, the development of extracurricular sports activities will play a vital role in the physical and mental health of students. It holds the key to cultivating students' interest and hobbies and shaping students' good habits in physical exercise.
\end{abstract}

\section{Introduction}

The importance of the initiative of high school students in college physical education to improve the teaching effect is discussed. Using the method of literature and observation and investigation and research in the universities sports teaching to improve the students' initiative, let students actively participate in sports classroom teaching modes and methods, and apply these methods to practical teaching observation after the students master the knowledge degree and improve the degree of personal qualities. As a result, students' initiative has been greatly improved, interest in learning has been fully mobilized, learning concentration has been focused, teaching process has been accelerated, and teaching quality has been greatly improved. Conclusion it is very important to improve the student's initiative on the teaching effect of physical education in Colleges and universities.

This characteristics and rules of the organization of extracurricular sports activities research, analyzed characteristics of university students' extracurricular sports activities, combined with the survey of students extracurricular sports organizations opinions and suggestions, and found the investigation and analysis of Guangxi college students' extracurricular physical exercise, and provide a reference for the University sports management department.

\section{Not Enough Attention Have Been Paid Towards the Locking of Student Autonomy in Physical Education Teaching in China's Colleges and Universities}

At present, education in Colleges and universities in China is still dominated by exam oriented education. Under the pressure of "enrollment rate", parents and schools pay more attention to their children's performance. The importance of improving children's physique has not yet been fully recognized. The student body education classroom lack of enthusiasm and participation, most of the students in physical education is not too interested in some weariness.

In order to achieve the initiative, in Physical Education in Colleges and universities to fully mobilize every students to participate in sports initiative, let the students to fully understand the physical health of physical education plays a positive role, establish lifelong sports awareness of college students, we fully consider the "students" the teaching subject, try to improve students' autonomy the teaching content and teaching methods of the beneficial exploration and reform. 


\section{Analysis on the Reasons for Students' Lack of Initiative in Physical Education Class}

\subsection{Obsolete Teaching Content, Simple Teaching Method and Lacking of Lively Teaching Form Is Lacking}

The teaching mode of college sports is still taking the teacher as the teaching subject, teaching content is still dominated by competitive sports, the same basic teaching form and physical education in primary and secondary schools, can be said that the university sports teaching is actually a simple continuation of physical education in primary and secondary schools, the students had lost the PE freshness, lost their enthusiasm for physical education class.

\subsection{Unclear Studying Purpose, Tiring Handling for PE Classes and strong Inertness}

Through the discussion with the students, we find that the purpose of the students is varied. Some for health, some for their favorite sport, some even in order to lose weight, in every kind of learning to a large part of the physical education students just as a study at the University during the courses must be completed, just as simple passive participants or passive accept negative conflict.

\subsection{Teachers Ignore the Subject Position of Students}

In past physical education classes, teachers were dominant in the whole teaching process, while students only passively accepted, which severely obliterated the individuality of students, and ignored the initiative and creativity of students. Therefore, teachers are required to give up the long-term influence of traditional educational ideas, abandon the interference of old ideas, abandon their leading role in high altitude, transform their roles into organizers, guides and collaborators of students' learning, and take students as the main body of teaching.

\subsection{One Unified Target for Different Interested and Physical Condition Students}

According to the teaching materials issued by the unified national government and assessment criteria, teachers did not realize that students have some differences as individuals and lack awareness of discrimination. In this way, it is difficult to avoid some of the students with poor physical quality and poor professional skills.

\subsection{Students are Passively Participating in Sports for A Long Time, and Lack of Enthusiasm and Interest in Physical Education}

Because in primary and secondary school physical education, teachers arrange teaching contents, first do demonstrations, and then command students to complete actions. As time passes, students form a habit of passive sports. To change students' habits of passive learning and give full play to the main role of students, we should adopt different teaching methods. We should add students' interest in the teaching process and retrain students' enthusiasm and interest in sports learning.

\section{Some Ways to Improve Students' Initiative in Physical Education}

\subsection{Add A Number of Interesting, Entertaining and Small Sports Links on the Basis of the Teaching Contents Specified in the Syllabus}

We use the last ten minutes a number of activities, including two three foot run, kangaroo jump, fixed-point shooting, four synchronous, clip the ball, run, pull up against obstacles, jump rope, hoop, ball, roller coasterrelay race, not only let students edify sentiment in the game, to promote students' communication, but also promote the feelings between the students to build up a strong team consciousness, improve the students' learning enthusiasm and efficiency.

\subsection{Design Different Teaching Methods Carefully, Let the Students Participate in the Teaching Link, and Give Full Play to the Students' Autonomy and Creativity}

Encourage teachers to design various teaching methods in teaching organization, try to grasp the 
"new, special, live" principle, including the inquiry teaching method, teaching method, teachers and students of transposition of small group learning teaching method, game teaching method, emotional teaching method, the main purpose of the design is to let the students have the sense of fresh exercise, exercise to stimulate the enthusiasm of the students.

\subsection{Treat Students Differently on Their Physical Condition and Interest of Different Students}

Teachers should fully recognize the students' physical quality, training level, ability to accept other aspects of individual differences, teach students in accordance with their aptitude "tolerant" principle, try to make different levels and different ability of students to be able to feel the joy of movement, independent participation in teaching. Teachers should not take care of each student's study enthusiasm, scores of students to timely affirmation and praise, also harsh accusations and criticisms for the lack of students, to enable students to recognize their gap in teacher's smile, in the teacher's care and love enhancing confidence, progress.

\subsection{Adjust the Teaching Content Appropriately with the Development of the Society and Student}

School physical education is the basis of lifelong physical education, and sports interest and habit are the precondition of promoting students' self-study and lifelong exercise. The teacher according to their interests and hobbies adjust teaching content and proportion, opening into the teaching process is temporarily unable to form interest classes in their spare time to open (such as yoga, climbing, training and so on), the main purpose is to fully mobilize the initiative and enthusiasm of students to participate in sports, promote the students enjoy the sport to bring happiness spontaneously, so as to form lifelong sports view.

Allow students enhance physical fitness is the main function of physical education, physical education plays any role must have this function which now has become the innovation education based on the requirements, but, according to a survey of China's current situation of the sports class, sports class action very little even, enhance the basic role of students constitution no, not to mention the effect on higher level students. Now the physical education class from the overall view is relatively vague, such as the physical education class, but did not provide special sports textbooks, what should be taught here? What is the best degree of teaching, and so on, is the blur of physical education. It also causes teachers to use old methods to teach students old-fashioned content in order to strive for the insurance of physical education. Put innovation in a distant place, which will make the teachers dare not break through in the face of innovation, physical education is more and more inconsistent with students, and the quality of physical education is deteriorating.

\section{Factors Affecting Extracurricular Physical Exercise}

A considerable portion of the student's spare time is occupied by other activities. More and more people choose to play computer in extracurricular time. The impact of computer and online games is rather strong and inevitable. Students' sports time and interest are greatly impacted.

Schools should increase the publicity of sports, create and highlight the atmosphere of sports culture. In terms of creating sports environment, we should start from two aspects: hard environment and soft environment. The school should increase the investment of the construction of the stadium as much as possible, and provide the necessary activities, equipment and adequate physical education teachers. At the same time, it is more flexible in teaching mode and teaching method, transforming closed sports education into open education, providing students with colorful teaching contents, flexible teaching time and so on. Only by cultivating students' interest, hobbies and habits in sports, and creating a strong campus sports culture atmosphere and deepening their sports awareness, can they become active participants and communicators of lifelong sports, which is also a key problem to solve extracurricular sports tasks. 


\section{Improve the Students' Initiative on the Effect of Physical Education}

The traditional PE used "filling duck" way. Our university has made the beneficial attempt in improving students' sports learning initiative and enthusiasm, through a period of observation we found that students in the PE class conflict, negative emotion significantly reduced, sport confidence of many students is to stimulate, students' actively participate in sports in the classroom. The physical quality of students is also improving under the condition of imperceptibly. The achievement standards of College Students' Sports qualification standards have been significantly improved compared with the previous ones. So to improve the students' initiative can not only improve the effect of college physical education teaching, but also cultivate the sports interest and habit is essential for students to establish lifelong sports consciousness, so the role of physical education in Colleges and universities in research on improving the students' initiative is very necessary.

\section{Conclusions}

The teaching of physical education should not be simple and obsolete, and do not understand the renewal. On the contrary, we should pay more attention to its comprehensiveness. That is to say, in the course of sports teaching, we should constantly develop new theories, and then guide the teaching practice based on this. Start in the teaching purpose and facilities and more seriously, with the various aspects of the teaching factors be all-round consideration. And in the combination of theory and practice to improve the degree of concern. In the aspect of students, actively help them establish a correct sense of learning.

\section{References}

[1] Wang Weixian. An analysis of how to improve students' lifelong physical awareness, Science public (Science Education), 2009, (10):55.

[2] Wang Dapeng. Analysis on the necessity and feasibility of developing Club Sports Teaching for graduate students in Colleges and universities, Journal of Hebei Normal University (EDUCATION SCIENCE EDITION), 2008 (08).

[3] Yang Baili. Quality education calls for differential teaching, Jilin education, 2006, (10): 33-34.

[4] Ji. Bulletin of the Virunga involvement and development of sports learning in sports teaching design -- and for 2001-2011 years: learning research literature review of primary and middle school sports, Sports scientific literature schools. 2011, (10).

[5] Huo Jun. Research on theory and practice of physical education method under the concept of innovative education, Beijing Sport University, 2014, (05).

[6] Mingjun Xin,Hanxiang Wu,Zhihua Niu. A Quick Emergency Response Model for Micro-blog Public Opinion Crisis Based on Text Sentiment Intensity, Journal of Software. 2012 (6).

[7] Zhou Hongwei. Research on the construction and development of outdoor sports sports features in Colleges and Universities -- Taking Zhejiang agroforestry University as an example of, sports science and technology literature, 2016,33 (03): 22-25.

[8] Su Xiaohong, Wang Xiaochun. Research on the present situation of the evaluation of physical education in Colleges and Universities under the new teaching idea, Journal of Shenyang Sport University, 2011 (06). 